DOI: https://doi.org/10.30749/2594-8261.v2n3p32-46

\title{
COMO ENTENDER HEIDEGGER? OS TEOREMAS DA DIFERENÇA ONTOLÓGICA E DO CÍRCULO HERMENÊUTICO
}

\section{HOW TO UNDERSTAND HEIDEGGER? THE THEOREMS OF THE ONTOLOGICAL DIFFERENCE AND THE HERMENETIC CIRCLE}

Cleyson de Moraes Mello*

Resumo: A hermenêutica filosófica em Heidegger assume um viés transformador. Daí a necessidade de compreender os teoremas da diferença ontológica e do círculo hermenêutico a partir do ser-no-mundo. É, neste sentido que, em face da flagrante inefetividade da hermenêutica clássica, originariamente metodológica, torna-se necessária à construção de uma resistência teórica que aponte para a construção das condições de possibilidade da compreensão de sentido, como modo de ser-nomundo.

Palavras-chave: Heidegger. Ser-no-mundo. Dasein.

Abstract: Heidegger's philosophical hermeneutics takes on a transformative bias. Hence the need to understand the theorems of ontological difference and the hermeneutic circle from being-in-the-world. It is in this sense that, given the striking ineffectiveness of classical hermeneutics, methodological in your origin, it is necessary to construct a theoretical strength that point to the construction of the conditions of possibility of understanding the sense, as a way of being-in-the-world.

Keywords: Right. Human dignity. Being-in-the-world, Dasein.

"Professor Adjunto do Departamento de Teoria e Fundamentos do Direito da Faculdade de Direito da UERJ. Doutor em Direito pela Universidade Gama Filho (2006), mestre em Direito pela Universidade Estácio de Sá (2001) e graduado em Direito pela Universidade Estácio de Sá (1999). 


\section{INTRODUÇÃO}

Heidegger, por meio da fenomenologia hermenêutica, critica e supera a fenomenologia subjetivista (objetivista) transcendental de Husserl. O rompimento da subjetividade do pensamento ocidental é realizado por um método fenomenológico que se conforma com a própria estrutura do ser-aí, que visa precisamente a superação do esquema sujeito-objeto.

Com isso, a ontologia fundamental de Heidegger ganha destaque e a questão do sentido do ser é colocada como uma questão privilegiada. O ser dos entes não "é" em si mesmo um outro ente (HEIDEGGER, 2002, p.32). O Dasein (Ser-aí, Pre-sença) é o ente privilegiado que compreende o ser e tem acesso aos entes. Ele faz parte da condição essencial do ser humano. Nas palavras de Heidegger: "esse ente que cada um de nós somos e que, entre outras, possui em seu ser a possibilidade de questionar, nós o designamos com o termo pre-senca." (HEIDEGGER, 2002, p.33). O ser-aí sempre se compreende a si mesmo a partir da sua existência. A análise das estruturas ontológicas do ser-aí é um existencial. Isso significa dizer que os caracteres não são propriedades de algo simplesmente dado, mas modos de ser essencialmente existenciais. Heidegger afirma que a pre-sença (ser-aí, dasein) "é um ente que, na compreensão de seu ser, com ele se relaciona e comporta." (HEIDEGGER, 2002, p. 90).

Assim, o Dasein, pela compreensão, inaugura uma circularidade. É, pois, uma circularidade hermenêutica. Ou seja, a recíproca relação entre ser e ente somente ocorre porque há o Dasein, isto é, porque há compreensão. Assim, o acesso ao ser é colocado a partir da compreensão do ser e tal compreensão é dada a partir da compreensão que o Dasein possui de si mesmo. Nesse sentido, o círculo hermenêutico e a diferença ontológica são os pilares que suportam a teoria heideggeriana. Em relação à metafísica, colocam-se novos paradigmas: o ser é entendido por um conceito ontológico dado pela compreensão e a diferença entre ser e ente impede a entificação do ser (matriz da tradição metafísica).

A diferença ontológica é a diferença entre ser e ente, uma vez que o ser é o elemento através do qual ocorre o acesso aos entes, isto é, sua condição de possibilidade. Essa condição é realizada por meio da compreensão pelo Dasein, 
pelo ser humano que se compreende e que sempre se dá pelo círculo hermenêutico. Dessa forma, a circularidade hermenêutica substitui o modelo da tradição metafísica ancorado na relação sujeito-objeto. De acordo com um modo de ser que lhe é constitutivo, a pre-sença tem a tendência de compreender seu próprio ser a partir daquele ente com quem ela se relaciona e se comporta de modo essencial, primeira e continuamente, a saber, a partir do "mundo". O ser-no-mundo é uma constituição necessária e a priori da pre-sença (HEIDEGGER, 2002, p.91).

A compreensão é a própria abertura do ser-no-mundo, bem como é um existencial. Destarte, todo o compreender é derivado dessa compreensão existencial, que é a própria luz, iluminação, abertura, clareira, revelação do ser-aí, Alethéia. Considerando que a compreensão é um existencial, não existe explicação sem a prévia compreensão. Melhor dizendo: o sentido alcançado pela explicação já nos é dado, na própria explicação, ou seja, o sentido faz parte da própria estrutura prévia da compreensão. A compreensão e a explicação constituem existencialmente a pre-sença (ser-aí). Portanto, é a compreensão prévia um existencial do ser-aí que como sua abertura, clareira, luz sempre se apresenta à medida que é buscada. Aí está o círculo hermenêutico. Nas palavras do próprio Heidegger, esse círculo da compreensão "não é um cerco em que se movimentasse qualquer tipo de conhecimento. Ele exprime a estrutura-prévia existencial, própria da pre-sença." (HEIDEGGER, 2002, p.210). Segundo Heidegger, nele se esconde a possibilidade positiva do conhecimento mais originário. ${ }^{1} \mathrm{O}$ que o filósofo procura mostrar é que devemos compreender as coisas de modo originário e autêntico, "a partir das coisas elas mesmas" desatrelado e desvinculado dos conceitos ingênuos e opiniões que a tradição em si as carrega. Portanto, o círculo da compreensão pertence à estrutura do sentido, cujo fenômeno tem suas raízes na constituição existencial da pre-sença,

\footnotetext{
${ }^{1}$ Heidegger ensina que no círculo da compreensão se esconde o conhecimento mais originário e só pode ser apreendido de modo autêntico, se a interpretação tiver compreendido que sua primeira, única e última tarefa é de não se deixar guiar, na posição prévia, visão prévia e concepção prévia, por conceitos ingênuos e "chutes". Ela deve, na elaboração da posição prévia e concepção prévia, assegurar o tema científico a partir das coisas elas mesmas. Isto porque a compreensão, de acordo com seu sentido existencial, é o poder-ser da própria pre-sença, as pressuposições ontológicas do conhecimento histórico ultrapassam, em princípio, a ideia de rigor das ciências mais exatas. A matemática não é mais rigorosa do que a história. É apenas mais restrita, no tocante ao âmbito dos fundamentos existenciais que lhe são relevantes. (HEIDEGGER, 2002, p. 210).
} 
enquanto compreensão que interpreta. Por conseguinte, o círculo da compreensão sustenta o método fenomenológico hermenêutico de Heidegger.

Hans-Georg Gadamer, na obra Verdade e Método II, também discorre sobre o círculo da compreensão (1959) e informa a necessidade em manter o olhar firme para as coisas elas mesmas, até o momento de superar as errâncias que atingem o processo de interpretação. Alerta, ainda, que quem quiser compreender um texto deverá sempre realizar um projeto. O intérprete deverá projetar de antemão um sentido do todo, tão logo se mostre um primeiro sentido no texto. Vale destacar que esse primeiro sentido somente se mostra porque lemos o texto já sempre com certas expectativas, na perspectiva de um certo sentido. A compreensão daquilo que está no texto consiste na elaboração desse projeto prévio, o qual sofre uma constante revisão à medida que aprofunda e amplia o sentido do texto (GADAMER, 2002, p. 75).

É através do método fenomenológico que as estruturas do ser-aí são explicitadas e que trazem em si a possibilidade de antecipação do sentido do ser pela pré-compreensão. O sentido da pre-sença é dado pela temporalidade (Zeitlichkeit), ou seja, o tempo é o ponto de partida do qual a pre-sença (ser-ai) sempre compreende e interpreta o seu ser. Dessa forma, o ser-aí é de tal modo que realiza uma compreensão do ser no horizonte do tempo. É dessa forma que, em Ser e Tempo, Hedeigger sustenta a tese da Pre-sença e Temporalidade (Segunda Seção de Ser e Tempo) que faz desmoronar radicalmente a equivalência metafísica entre ser e eternidade.

Por outro lado, a abertura do ser-aí, ou seja, o ser do ser-aí é a preocupação (cura, sorge). Essa é a luz que constitui a luminosidade da pre-sença, isto é, aquilo que o torna "aberto" e também "claro" para si mesmo. É a cura que se funda toda abertura do pre e a temporalidade ekstática que o ilumina originariamente. Heidegger afirma que somente partindo do enraizamento da pre-sença na temporalidade que se consegue penetrar na possibilidade existencial do fenômeno, ser-no-mundo, que, no começo da analítica da pre-sença, fez-se conhecer como constituição fundamental (HEIDEGGER, 2002, p.150).

Heidegger leva a cabo uma investigação ontológica "concreta", partindo do ente que compreende o ser, ou seja, único para o qual há ser, a saber, o próprio 
homem (vale destacar que aqui não há falar-se de "consciência" ou "sujeito" da filosofia moderna). O homem é Dasein. O filósofo afirma: "a pre-sença (Dasein) existe. Ademais, a pre-sença é o ente que sempre mesmo eu sou." (HEIDEGGER, 2002, p.90). Logo, Dasein é existência, ou seja, o fato de ser fora de si, de possuir uma estrutura ekstática, em detrimento ao sujeito da filosofia moderna fechado sobre si mesmo (Ser e Tempo, § 69). A abertura essencial do ser do homem é chamada cuidado, preocupação e o sentido propriamente temporal da existência enquanto modo de ser humano é a temporalidade. É o pôr à luz com sentido temporal da existência enquanto modo de ser humano. Daí a ontologia da finitude, já que o Dasein é finito, isto é, mortal (Ser e Tempo, Primeiro Capítulo da Segunda Seção A possibilidade da Pre-sença ser-toda e o ser-para-a-morte).

Assim, Heidegger propõe a tese da finitude do tempo original, em detrimento à tese clássica da infinitude do tempo da natureza. Assim, podemos dizer que não há ser nem tempo senão na medida em que há Dasein. O Dasein dá a si mesmo o seu tempo. O fundamento ontológico originário da existencialidade da pre-sença é a temporalidade. A totalidade das estruturas do ser da pre-sença articuladas na cura só se tornará existencialmente compreensível a partir da temporalidade (HEIDEGGER, 2004, p. 13). Portanto, é na temporalidade que Heidegger vai buscar o sentido da pre-sença (ser-aí), isto é, da preocupação. O filósofo afirma em Ser e Tempo

\begin{abstract}
Se a temporalidade constitui o sentido ontológico originário da presença, onde está em jogo o seu próprio ser, então a cura deve precisar de 'tempo' e, assim, contar com o 'tempo'. A temporalidade da pre-sença constrói a 'contagem do tempo'. O 'tempo' nela experimentado é o aspecto fenomenal mais imediato da temporalidade. Dela brota a compreensão cotidiana e vulgar do tempo. E essa se desdobra, formando o conceito tradicional de tempo. (HEIDEGGER, 2004, p. 13-14).
\end{abstract}

A compreensão do ser é tornada possível mediante a temporalidade ekstática do Dasein, ou seja, o tempo passa a ser o locus da compreensão do Dasein. É, com efeito, no $\S 65$ de Ser e Tempo que a temporalidade é revelada como constituindo o sentido do cuidado, sorge, cura. Heidegger afirma que "enquanto cura, a totalidade ontológica da pre-sença diz: preceder-se-a-si-mesma- 
em (um mundo) enquanto ser-junto-a (entes que vêm ao encontro dentro do mundo)." (HEIDEGGER, 2004, p. 121). Assim o filósofo fixou a articulação da estrutura originária da cura na temporalidade. Isso quer dizer que o Dasein (presença) nunca perde a sua integralidade; que ela perdura no tempo, porque ele é formado por momentos inseparáveis uns dos outros. Daí Heidegger falar em estrutura do ser-aí. Esta estrutura fundamental é chamada ser-no-mundo.

Pertence à estrutura ontológica da pre-sença uma compreensão do ser. É sendo que a pre-sença está aberta para si mesma em seu ser. Há que se buscar uma abertura mais abrangente e mais originária dentro da própria pre-sença (Dasein). (HEIDEGGER, 2002, p.245).

Portanto, não é no terreno da quotidianidade que vamos conseguir encontrar a unidade do Dasein (pre-sença). Isso porque a interpretação cotidiana da pre-sença encobre onticamente o ser próprio da pre-sença (HEIDEGGER, 2004, p.104). Assim, o modo de ser da pre-sença exige uma interpretação ontológica. A interpretação ontológica projeta o ente preliminarmente dado em seu próprio ser, de modo a chegar ao conceito de sua estrutura. Assim, originariamente constituída pela cura, a pre-sença (Dasein) já sempre precede-a-si-mesma. Daí a importância do círculo hermenêutico. É o salto para dentro do círculo hermenêutico que assegura o ponto de partida da análise do Dasein (pre-sença). O próprio desejo e esforço para fugir do círculo reside na condição de decaída da pre-sença. Segundo Heidegger, este termo não exprime qualquer avaliação negativa. Pretende apenas indicar que, em primeira aproximação e na maior parte das vezes, a pre-sença está junto e no "mundo" (HEIDEGGER, 2004, p.109).

Este estar junto possui, frequentemente, o caráter de perder-se na publicidade do impessoal, eis que a própria pre-sença já sempre caiu de si mesma e de-caiu no "mundo". 2 fenômeno da de-cadência apresenta-se em um modo

\footnotetext{
2 Nesse sentido, Heidegger afirma que "a de-cadência da pre-sença também não pode ser apreendida como 'queda' de um 'estado original', mais puro e superior. Disso nós não dispomos onticamente de nenhuma experiência e, ontologicamente, de nenhuma possibilidade e guia ontológicos para uma interpretação. Enquanto ser-no-mundo de fato, a pre-sença na de-cadência, já de-caiu em algo ôntico com o que ela se deparou ou não se deparou, no curso de seu ser, e sim no mundo que, em si mesmo, pertence ao ser da pre-sença. A de-cadência é uma determinação existencial da própria pre-sença e não se refere a ela como algo simplesmente dado, nem a relações simplesmente dadas com o ente do qual ela 'provém', ou com a qual ela posteriormente entra em commercium." (HEIDEGGER, 2002. p. 236-237).
} 
existencial de ser-no-mundo. Em sua obra Sobre o Humanismo, Heidegger (1995, p. 53) afirma que o esquecimento da Verdade do Ser em favor da avalanche do ente, não pensado em sua essência, é o sentido da "decadência", mencionada em Ser e Tempo.

A possibilidade da decadência enquanto imersão no mundo tem a sua origem na fuga do Dasein (pre-sença) perante si mesmo. No falatório ${ }^{3}$ e na interpretação pública, a própria pre-sença (Dasein) confere a si mesma a possibilidade de perder-se no impessoal e de de-cair na falta de solidez. Isso porque a própria pre-sença prepara para si mesma a tentação constante de de-cair.

Heidegger afirma que o ser-no-mundo já é em si mesmo tentator e, desta forma esta tentação, através da interpretação pública mantém a pre-sença presa à sua de-cadência. A pretensão do impessoal, no sentido de nutrir e dirigir toda a vida autêntica, tranquiliza a pre-sença, assegurando que tudo "está em ordem". Nesse sentido o ser-no-mundo da decadência é, em si mesmo, tentador e tranquilizador.

É neste sentido que Ernildo Stein (2001, p. 256) afirma que, na preocupação como decaída está radicada a tendência de senso comum de experimentar o ente real, para poder fugir e se distanciar da verdadeira compreensão do ser. O senso comum desconhece o fato de que somente pode conhecer realmente o ente se o ser já foi conhecido, ou seja, através do viés ontológico.

Nas palavras de Heidegger:

Mas o que propriamente se deve compreender permanece, no fundo, indeterminado e inquestionado; não se compreende que compreender é um poder-ser que só pode ser liberado na pre-sença mais própria (HEIDEGGER, 2002, p. 239).

É nesse sentido que Heidegger (2002, p.240) entende que o ser-no-mundo da de-cadência é em si alienante, já que ocorre o encobrimento do seu poder-ser mais próprio. Essa alienação gera um aprisionamento (prisão) da própria pre-sença em seu sentido mais originário. Dessa forma, Heidegger caracteriza os fenômenos da de-cadência como: tentação, tranqüilidade, alienação e aprisionamento (prisão).

\footnotetext{
${ }^{3}$ Heidegger entende falatório como a abertura para a pre-sença, numa compreensão, o ser para o seu mundo, para os outros e para consigo mesma, mas de maneira a que esse ser para conserve o modo de oscilação sem solidez. O falatório é o modo de ser da própria convivência. (HEIDEGGER, 2002, p.238-239).
} 
Essa "mobilidade" da pre-sença em seu próprio ser é chamada de precipitação, ou seja, a pre-sença "se precipita de si mesma para si mesma na falta de solidez e na nulidade de uma cotidianidade imprópria.". É mediante a interpretação pública que essa precipitação fica velada para a pre-sença, sendo interpretada como "ascensão" e "vida concreta" (HEIDEGGER, 2002, p.240).

A possibilidade da decadência enquanto imersão no mundo tem a sua origem na fuga da pre-sença (Dasein) perante si mesmo como seu próprio poder-ser propriamente. Assim, do ponto de vista existencial, o Dasein (pre-sença) na fuga, fecha-se a si mesmo como pre-sença. "É justamente daquilo de que foge que a presença corre atrás." (HEIDEGGER, 2002, p.248). O desvio da decadência se funda na angústia que, por sua vez, torna possível o temor (HEIDEGGER, 2002, p.249). Aquilo com que a angústia se angustia é o ser-no-mundo como tal e o angustiar-se abre, de maneira originária e direta, o mundo como mundo (HEIDEGGER, 2002, p.249-251).

Assim, a angústia torna visível a existência de fato que é a própria imersão no mundo, ou seja, é o momento do de-caído que caracteriza o ser em modo impróprio do Dasein, qual seja: a sua inautenticidade. Dessa forma, constitui as estruturas do cuidado (sorge), ao lado da faticidade e da existencialidade, a decadência (estar-caído), quando esta última só caracteriza a preocupação do serno-mundo quotidiano e inautêntico.

Daí que a fórmula existencial pela qual Heidegger (2004, p. 110) explicita o ser do Dasein como Cuidado (Cura) é preceder-a-si-mesmo-em (um mundo) enquanto ser-junto-a (um ente intramundano que vem ao encontro). Desse modo, o ser do ser-aí é a preocupação e o sentido desta é a temporalidade. É, portanto, a temporalidade que torna possível a unidade da existencialidade, da faticidade e da decadência, enquanto momento estruturais do cuidado. Todavia, o mundo é, ao mesmo tempo, o "lugar" do passado-presente-futuro: temporalidade.

É na conferência Tempo e Ser de 1962 que Heidegger apresenta uma nova perspectiva da temporalidade do ser. Nesse momento, sob o nome de Ereignis, é pensado, diferentemente de todas as distinções metafísicas, a co-apropriação do 
tempo e do ser. O filósofo esclarece que cada coisa tem seu tempo, ou seja, cada coisa que sempre é a seu tempo. Ser, porém, não é alguma coisa. Logo não está no tempo. Todavia, ser permanece como pre-sentar, como pre-sença determinada pelo tempo, já que possui caráter temporal (HEIDEGGER, 1972, p.42). Não obstante, "tempo não é coisa, e por conseguinte, nada de entitativo; mas permanece constante em seu passar, sem mesmo ser nada de temporal como o é o ente no tempo." (HEIDEGGER, 1972, p.42). Dessa forma, ser e tempo se determinam-se mutuamente, de tal forma que o ser não pode ser abordado como temporal e o tempo como entitativo.

Portanto, ser e tempo não são coisas (algo entitativo) e não podemos dizer ser é, tempo é; mas dá-se ser e dá-se tempo. "Ser, pelo qual é assinalado todo o ente singular como tal, ser significa pre-sentar. Pensado sob o ponto de vista do que se presenta, pre-sentar se mostra como pre-sentificar." (HEIDEGGER, 1972, p.44). Pre-sentificar mostra-se no que the é próprio como desvelar, levar ao aberto. Portanto, a questão nodal é pensar o 'ser' naquilo que Ihe é próprio, ou seja, no presentificar que do interior do desvelar fala um dar, um dá-Se. O dar no dá-Se quer dizer destinar. O próprio do ser nada tem de caráter ôntico. Heidegger (1972, p.42) afirma: "Ser quer dizer: pre-s-entar, presenti-ficar, pre-s-ença", alertando que não estamos acostumados a determinar o que é próprio do tempo, tomando como referência o presente no sentido da pre-s-ença. De forma contrária, representamos o tempo - a unidade de presente, passado e futuro - a partir do agora. O tempo visto como uma sucessão de "agoras" (passado como "há pouco" e futuro como "logo-a seguir"). O filósofo (HEIDEGGER, 1972, p.51) destaca que o tempo é conhecido como uma sucessão de "agoras", quando se mede e calcula o tempo. Assim, na conferência Tempo e Ser, é buscado um âmbito mais originário para o sentido de tempo, até então impensado, e que esconde no ser como como presentar. O tempo mesmo não é nada de temporal e nada de entitativo. Daí futuro, passado e presente fazem parte de uma unidade em seu recíproco-alcançar-se, ou seja, sua unidade

\footnotetext{
${ }^{4}$ Heidegger explica: "O caminho apropriado nesta direção consiste em examinarmos o que é dado no 'dá-se', que significa 'ser', que - dá-se; que significa 'tempo', que - dá-se. De acordo com isto, procuramos investigar o 'se', que dá ser e tempo. Procedendo desta maneira, tornamo-nos previdentes em um outro sentido." (HEIDEGGER, 1972, p.44).
} 
unificante só pode determinar-se a partir do que lhes é próprio. ${ }^{5}$ Ora, o presentar neles alcançado ilumina o espaço-de-tempo. Este designa o aberto, que se ilumina no recíproco alcançar-se de futuro, passado e presente. O iluminador alcançar-serecíproco de futuro, passado e presente é pré-espacial e, somente desta forma, pode delimitar espaço, ou seja, dar. É aí que Heidegger (1972, p.55) fala de tempo autêntico. A dimensão do tempo repousa no alcançar iluminador "como aquilo que traz o passado, o passado, o futuro, e a relação mútua de ambos a clareira do aberto". Esse trazer é o presentar, tanto no advento do ainda-não-presente (futuro), como no não-mais presente (passado), como no presente, ou seja, nessas três dimensões (passado, presente, futuro) sempre está em jogo uma "espécie de abordagem e um trazer para". Daí surge o tempo como quadrimensional. Heidegger (1972, p.55) explica:

\begin{abstract}
Essa unidade das três dimensões repousa, muito antes, no proporcionar-se cada uma à outra. Este proporcionar-se mostra-se como o autêntico no alcançar que impera no que é próprio do tempo, portanto, como uma espécie de quarta dimensão - não apenas uma espécie, mas uma dimensão efetivamente real.

O tempo é quadrimensional.

O que, porém, na enumeração, chamamos de quarta dimensão é, de acordo com a realidade, a primeira, isto é, o alcançar que a tudo determina. Este produz, no porvir, no passado, no presente, o presentar que é próprio a cada um, os mantém separados pelo iluminar, e os retém, de tal maneira, unidos um ao outro, na proximidade, a partir da qual permanecem reciprocamente próximas, as três dimensões.
\end{abstract}

\footnotetext{
${ }^{5}$ Este assunto, também, é tratado por Heidegger no Seminário de 18 a 21 de Janeiro de 1965, na casa de Boss. Vejamos as lições heideggerianas: "Chamamos o passado, o futuro e o presente de dimensões do tempo, sem definir agora o que 'dimensão' significa aqui. Geralmente, fala-se de dimensão em relação ao espaço tridimensional. Diz-se do tempo, pensado como uma seqüência de aogoras e representado como linha, que ele é unidimensional, e que o presente, passado e futuro não são contemporâneos como as dimensões do espaço, mas sempre só subseqüentes. Visto assim, pode parecer estranho, inicialmente, falarmos de três ou até quatro dimensões de tempo e dizer que elas são contemporâneas e não subseqüentes. Mas, pelo visto, estas dimensões nada têm a ver com o espaço. Todas as três dimensões do tempo são co-originárias, pois não há uma sem a outra, todas as três são, para nós, co-originariamente abertas, mas não são eqütiativamente abertas. Ora uma, ora outra dimensão com a qual nos relacionamos, em que talvez estejamos até presos, é determinante. Nem por isso as outras duas dimensões desaparecem em cada caso, apenas são modificadas. As outras dimensões não subjazem a uma simples negação, mas a uma privação." (HEIDEGGER, 2001. p.75).
} 
É, pois, o tempo autêntico a proximidade unificante do tríplice alcançar iluminador de presença a partir do presente, passado e futuro. O dar no "dá-Se tempo" se mostrou como o alcançar iluminador do âmbito quadrimensional. É assim que o destinar de ser, como tempo é encontrado no sentido do alcançar iluminador. E deste modo chega Heidegger (1972, p.59) ao chamado Ereignis.

No destinar do destino do ser, no alcançar do tempo, mostra-se um apropriar-se trans-propriar-se do ser como presença e do tempo como âmbito do aberto, no interior daquilo que Ihes é próprio. Aquilo que determina a ambos, tempo e ser, o lugar que lhes é próprio, denominamos: das Ereignis (o acontecimento-apropriação).

O Ereignis deve ser pensado como o acontecimento-apropriação, ou seja, no sentido que se anuncia no destinar da presença e no alcançar iluminador do espaço-de-tempo. Heidegger (1972, p.59) alerta que, ainda assim, permanece indeterminado falar do "ser enquanto Ereignis", porque o "enquanto" ("als") é sempre capcioso. Na expressão "Ser enquanto Ereignis", o "enquanto" quer dizer "Ser, presentificar destinado no acontecer que apropria, tempo alcançado no acontecer que apropria. Tempo e ser acontecem apropriados no Ereignis."

Desta forma e na medida em que ser e tempo só se dão no acontecer apropriador, deste faz parte o elemento característico que consiste em levar o homem, como aquele que percebe ser, insistindo no tempo autêntico, ao interior do que Ihe é próprio. Assim apropriado o homem pertence ao Ereignis (HEIDEGGER, 1972, p.63).

Nesse sentido, também no texto El principio de identidad, texto modificado de uma conferência pronunciada por Heidegger, 27 de junho de 1957, por ocasião dos 500 anos de vida da Universidade de Friburgo em Brisgovia, o filósofo já mencionava a apropriação do homem e ser reciprocamente

Pues el hombre es el primero que, abierto al ser, deja que éste venga a él como presencia. Tal llegada a la presencia necesita de lo abierto de um claro, y com esta necessidad, pasa a ser propia del hombre. Esto no quiere decir de ningún modo que el ser sea puesto sólo y em primer lugar por el hombre; por el contrario, se ve claramente lo seguinte: el hombre y el ser han pasado a ser proprios el uno del outro. Pertencen el uno al outro.

$[\ldots]$ 
De lo que se trata es de experimentar sencillamente este juego de propiación em el que el hombre y el ser se transpropian recíprocamente, esto es, adentrarnos em aquello que nombramos Ereignis. La palabra Ereignis há sido tomada de la lengua actual. Ereignen significa originariamente: asir com los ojos, esto es, divisar, llamar com la mirada, a-propriar. (HEIDEGGER, 1990, p. 77-78).

Desse modo, o pensamento heideggeriano caminha no sentido de analisar o homem não como um ente em meio aos outros entes (estrutura ôntica), mas procura analisar o homem a partir da abertura que nele é a própria manifestação do ser.

Portanto, em Ser e Tempo, o pensamento heideggeriano é no sentido do esquecimento do ser (velamento, ocultação). Tal velamento do ser faz parte (como sua privação) da clareira do ser. Na conferência Tempo e Ser, Heidegger procura pensar o ser, perpassando pela análise do tempo autêntico, naquilo que lhe é mais próprio, qual seja: Ereignis, ou seja, um retorno ao fundamento, a origem.

No final da conferência Tempo e Ser, quando Martin Heidegger (1972, p.65) afirma que "pensar ser em o ente, quer dizer: pensar ser sem levar em consideração a metafísica. Mas uma tal consideração impera ainda mesmo na intenção de superar a metafísica." Isto não quer dizer que a relação de ser e ente não seja essencial; pelo contrário, não devemos pensar tal relação como a metafísica o pensa. Assim, a relação de ser e ente deve ser vista no caráter metafísico, a partir da diferença ontológica. Quando Heidegger pensa o ser e o ente a partir da diferença ontológica, busca dar um sentido mais original a ambos. Dessa maneira, o conceito de ser, em Heidegger, é pensado a partir da diferença ontológica, no sentido de que ao compreendermos o mundo, nele compreendemos a nós mesmos. Está aí a circularidade da finitude. É a ontologia da finitude, a ontologia fundamental, analítica existencial, base da desconstrução da metafísica proposta por Heidegger, fincadas pelos teoremas da circularidade hermenêutica e diferença ontológica introduzidas pela compreensão do ser.

Dessa maneira, Dasein é um ser-no-mundo. Este modo de ser-no-mundo é o cuidado, a cura, a preocupação, que é o ser do ser-aí. O sentido do ser-aí é dado pela temporalidade com caracteres existenciais. O espaço em que acontece 0 Dasein está limitado, finitizado no mundo. É a tríplice dimensão da estrutura da temporalidade (passado-presente-futuro) que informará o conceito fundamental de 
finitude heideggeriano. ${ }^{6}$ A temporalidade, enquanto índice da finitude do ser-aí, torna-se, assim, o horizonte necessário para a interrogação pelo sentido do ser (STEIN, 2001, p. 291). Dessa forma, a interrogação pelo ser deve ser norteada pela finitude do ser-aí, já que o ser ligado ao tempo não pode ser interpretado a partir da eternidade (negação do tempo). Vale destacar que a referida finitude somente se realiza na circularidade da relação ser-ser-aí (STEIN, 2001, p. 292).

O sentido do ser, dado pela temporalidade, é conseguido pelo desvelamento das estruturtas do ser-aí. Os existenciais são a essência do ser-aí e sua analítica é realizada no plano transcendental. Em Ser e Tempo, frise-se, Heidegger (2002, p.69) já afirmava: "A verdade fenomenológica (abertura do ser) é veritas transcendentalis." O ser e sua estrutura ontológica se acham acima de qualquer ente e de toda a determinação ôntica possível de um ente. O ser é o transcendens pura e simplesmente. A transcendência do ser da pre-sença é privilegiada porque nela reside a possibilidade da individualização mais radical. E, desta forma, toda e qualquer abertura do ser enquanto transcendens é conhecimento transcendental (HEIDEGGER, 2002, p. 69).

Vale destacar que não obstante Heidegger procurar desde o início superar a dimensão transcendental da metafísica (no sentido de sua superação), a analítica existencial do ser-aí (pre-sença) é realizada no plano transcendental. ${ }^{7}$ Consequentemente, resta estabelecido o sentido da compreensão da finitude do seraí na filosofia heideggeriana. A finitude do ser-aí impõe-se a partir da ambivalência velamento-desvelamento, ou seja, o homem é atingido pelo ser apenas como Alethéia, ou seja, desvelamento, clareira. O homem se abre como a clareira do ser. Stein (2001, p. 294-295) esclarece que "a finitude do homem se compreende,

\footnotetext{
${ }^{6}$ Nesse sentido, Ernildo Stein fincado no pensamento heideggeriano esclarece que Dasein é futuropassado-presente, no sentido de que ainda que ele se agarre ao presente, nesse presente já sempre está implícita a idéia da faticidade à qual se liga a idéia de hermenêutica. A idéia de futuro não é o futuro no qual vamos morrer, onde terminamos, etc... Mas é o futuro que nos move agora no presente, por isso o Dasein é ser-para-a-morte enquanto ser-no-mundo. Portanto, somos futuro, passado e presente, num único movimento. Somos, como diz o filósofo, definindo o conceito de cuidado: Sempre um adiante-de-nós, já-no-mundo, junto-das-coisas. Essa tríplice dimensão do cuidado da estrutura da temporalidade, é que dará a Heidegger o conceito fundamental de finitude. (STEIN, 2000. p. 57).

${ }^{7}$ Nessa perspectiva, o homem está relacionado com o sentido do ser, ou seja, está relação com o homem não ocorre por motivos antropológicos e/ou ônticos.
} 
portanto, como a relação que o homem instaura com o ser limitando-o em sua manifestação e velando-o."

No ser-aí, enquanto preocupação e temporalidade, enquanto finitude, o ser jamais pode irromper na plena manifestação de seu velamento e seu próprio mostrar-se é simplesmente um mostrar para a sua condição de velamento: aletheia. A finitude do ser-aí deve, portanto, ser compreendida como o fato de o ser-aí somente manifestar o ser velando-o, apontando para o velamento do ser. $\mathrm{O}$ ser-aí é, portanto, pensado e compreendido, como finitude, em função da finitude da compreensão do ser. O ser é finito porque é compreendido pelo ser-aí que é finito enquanto preocupação e temporalidade (STEIN, 2001, p. 295).

Com o conceito de finitude posto, Heidegger procura o acesso às estruturas do ser-aí, através da analítica existencial e supera, destarte, o esquema sujeitoobjeto. Daí o paradigma heideggeriano. O filósofo, ao criticar a metafísica, na verdade, é contrário à busca de um fundamento firme, objetificador ou um fundamento inconcusso (estável, inabalável). Nesse sentido é que o Dasein é abissal, sem fundo, posto que a sua fundamentação remete à pura possibilidade. Stein afirma que o fundamento heideggeriano não é nem realidade como um objeto ou como sujeito no qual se fundaria o conhecimento. O conhecimento é uma estrutura prévia, dada pela compreensão do ser. Portanto, o ser-aí, o ser-no-mundo, é a base de qualquer teoria do conhecimento.

\section{REFERÊNCIAS}

GADAMER, Hans-Georg. Verdade e Método II: Complementos e Índice. Tradução Enio Paulo Giachini. Petrópolis: Vozes, 2002.

HEIDEGGER, Martin. O Fim da Filosofia ou A Questão do Pensamento. Trad. Ernildo Stein. São Paulo: Livraria Duas Cidades, 1972.

HEIDEGGER, Martin. Identidad Y Diferencia. Trad. Helena Cortés e Arturo Leyte. Barcelona: Anthropos, 1990.

HEIDEGGER, Martin. Sobre o Humanismo. Trad. Emmanuel Carneiro Leão. 2.ed. Rio de Janeiro: Tempo Brasileiro, 1995. 
HEIDEGGER, Martin. Seminários de Zollikon. Trad. Gabriela Arnhold e Maria de Fátima de Almeida Prado. Petrópolis: Vozes, 2001.

HEIDEGGER. Ser e Tempo: Parte I, Tradução Marcia Sá Cavalcante Schuback.12.ed. Petrópolis: Vozes, 2002.

HEIDEGGER. Ser e Tempo: Parte II. 11.ed. Trad. Marcia Sá Cavalcante Schuback.11.ed. Petrópolis: Vozes, 2004.

STEIN, Ernildo. Diferença e Metafísica: Ensaios sobre a Desconstrução. Porto Alegre: EDIPUCRS, 2000.

STEIN, Ernildo. Compreensão e Finitude: Estrutura e Movimento da Interrogação Heideggeriana. ljuí, Rio Grande do Sul: Unijuí, 2001. 